\title{
Morphological Variations of Sacrum in Adult Indian Population
}

\section{Sandeep Saluja ${ }^{1}$, Sneh Agarwal ${ }^{2}$, Anita Tuli ${ }^{3}$, Shashi Raheja ${ }^{4}$, Sarika Rachel Tigga ${ }^{5}$.}

${ }^{1}$ Associate Professor, Department of Anatomy, ESIC Medical College \& Hospital, Alwar, Rajasthan, India.

${ }^{2}$ Director Professor \& Head, Department of Anatomy, Lady Hardinge Medical College and Associated Hospitals, New Delhi, India.

${ }^{3}$ Consultant, Department of Anatomy, Maulana Azad Medical College, New Delhi, India.

${ }^{4}$ Professor \& Head, Department of Anatomy, Dr. Baba Saheb Ambedkar Medical College \& Hospital, Delhi, India.

${ }^{* 5}$ Associate Professor, Department of Anatomy, ESIC Medical College \& Hospital, Alwar, Rajasthan, India.

\section{ABSTRACT}

Introduction: The sacrum is considered as a highly variable bone. Several morphological variations have been documented which exhibit differences in the frequency of occurrence and morphological characteristics in various study populations. Variant anatomy of the sacrum may be associated with backache, enuresis, neurological anomalies of the lower limb and functional disorders of lower urinary tract.

Purpose: The purpose of this study was to identify and describe morphological variations of sacrum in Indian population and enable comparison with different populations.

Materials and Methods: The study was conducted on 108 dry adult human sacra and morphological characteristics and variations were noted.

Results: Sacral skewness was observed in $7.4 \%$ sacra with right sided skewness being predominant. The presence of accessory auricular surface (AAS) was noted in 13\% sacra which was at the level of S3 vertebra in most sacra. Spina bifida (SB) was observed in $11.1 \%$ sacra and it was most commonly located at S1 vertebral level. Furthermore, the lumbo-sacral transitional vertebra (TV) was documented in $10.2 \%$ sacra.

Conclusions: Sacrum displays numerous variations in Indian population such as skewness, AAS, SB and TV. Thorough knowledge of morphological characteristics and variations of sacrum is vital and should be contemplated during diagnosis and treatment of sacrum-related diseases.

KEY WORDS: Accessory auricular surface, Spina bifida, Transitional vertebra, Sacral skewness, Variations.

Corresponding Author: Dr Sarika Rachel Tigga, Associate Professor, Department of Anatomy, Affiliation address: ESIC Medical College \& Hospital, Alwar, Rajasthan, India-301030 Phone: 9891466140 E-Mail: sarika.rachel@gmail.com

Access this Article online

Quick Response code

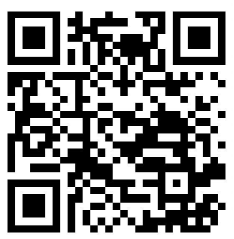

DOI: $10.16965 /$ ijar.2021.193

Journal Information

\section{International Journal of Anatomy and Research}

ISSN (E) 2321-4287 | ISSN (P) 2321-8967

https://www.ijmhr.org/ijar.htm

DOI-Prefix: https://dx.doi.org/10.16965/ijar

Article Information

Received: 30 Nov 2021

Peer Review: 01 Dec 2021
Accepted: 02 Jan 2022

Published (O): 05 Mar 2022

Published (P): 05 Mar 2022

\section{INTRODUCTION}

The sacrum is formed by union of five progressively smaller sacral vertebrae and their costal elements, sustaining the integrity of the spinal column. The bony framework of the true pelvic cavity is constituted postero-superiorly by the pelvic surface of the sacrum and coccyx. Its base forms the lumbo-sacral angle 
by articulating with the fifth lumbar vertebra, and the apex articulates with the coccyx [1]. In the anatomical position, superior surface of the base inclines downwards and forwards at $30^{\circ}$ or more [2]. The anteriorly projecting upper margin of the first sacral vertebra is the sacral promontory which constitutes an important obstetric landmark during clinical and radiological pelvimetry [3]. Lateral to the bodies of sacral vertebrae, is the wing like ala of sacrum on each side, comprising of fused costal elements and transverse processes. It has an auricular surface on its lateral side for articulation with the ilium, thereby completing the pelvic ring [2]. The sacrum contributes to the stability of the pelvic ring by its situation, being wedged between the two hip bones and also endures weight transmission. The transmission of weight to the sacrum is initially from its body and two articular facets and then through its two auricular surfaces to the hip bone [4].

The sacrum is recognized as a highly variable bone and numerous morphological variations have been reported [5]. Position and extent of the sacral auricular surfaces show variations which are normal, high up or low down, these may produce vertical shift in weight-bearing patterns between L5 and S1 segments, changing weight distribution at the lumbo-sacral and sacroiliac regions. This positional change of auricular surface can explain low back pain conditions [6]. In addition to the sacral auricular surface (AS), accessory auricular surfaces (AAS) are encountered, that may vary in measurement, location and laterality in each sacrum [7]. These usually result from stress of weight-bearing and could be frequently mistaken for an abnormal osseous projection (exostosis), especially when there is associated osteoarthritis or ankylosis [8].

Various developmental defects also plague the sacrum, most known being spina bifida (SB), a condition in which there is incomplete fusion of the vertebral neural arch. It is usually seen at lumbo-sacral region at the level of the fifth lumbar or upper one or two sacral vertebrae and occasionally may affect all the components of dorsal sacral arch [9]. SB may not present any external manifestations or its location may be marked by a dimple, hairy patch, haemangioma or pigmented area. Its clinical significance ranges from anatomical variants of little importance to strong association with clinical conditions such as posterior disc herniation, backache, enuresis, neurological abnormalities of the lower limb and functional disorders of lower urinary tract [10]. Presence of SB may enhance the chances of injury to the sacral nerves and cause hindrance in internal fixation of screws [11]. Knowledge of sacral SB assumes significant clinical importance during caudal epidural block [CEB] to avoid complications [10].

The lumbo-sacral spine plays an important role in posture and supports the weight of the body [12]. Lumbo-sacral transitional vertebrae (TV) are common congenital anomalies of the lumbo-sacral spine [13]. The sacrum may contain six vertebrae, by development of an additional sacral element or by incorporation of the fifth lumbar or first coccygeal vertebra. Complete or partial fusion of fifth lumbar vertebra with sacrum (sacralization) is seen in over $6 \%$ of normal population. It is usually incomplete and limited to one side and one or both transverse processes of L5 may be enlarged with reduced L5-S1 disc space [1]. Less frequently an extra lumbar vertebra due to lumbarization of S1 is also seen. The existence of transitional vertebrae may result in a vertebral level being wrongly identified unless detected preoperatively [14]. Lumbo-sacral transitional vertebrae (TV) are frequently named the culprit in the etiology of low back pain as they increase the risk for development of nerve-root symptoms $[15,16]$. Patients with lumbo-sacral TV have been reported with increased risk for advanced disc degeneration or disc herniation above the TV and facet joint arthrosis which can lead to stenosis of spinal canal and neural foramina [17].

Differences exist in the morphological characteristics of sacrum in various study populations. So far, out of the studies available, few determine the morphological variations of sacrum, especially in the Indian population. The present study is an attempt to describe morphological variations of the Indian sacra which are implicated in several 
clinical conditions.

\section{MATERIALS AND METHODS}

A cross-sectional observation study was done on 108 dry adult human sacra in Department of Anatomy. Sacra displaying damage or bony outgrowth were excluded from the study.

The following characteristics were observed:

1. Sacral skewness- An asymmetry of sacrum in which the middle sagittal line of pelvic surface skews to right or left, was noted.

2. Auricular surface (A.S.)- Surface and location of auricular surface was observed.

3. Accessory auricular surface (A.A.S.)- Shape, surface, location and unilateral or bilateral presence of accessory auricular surface were noted.

3. Sacral spina bifida: The number and vertebral level was documented for sacral spina bifida.

4. Lumbo-sacral transitional vertebra - Presence of lumbo-sacral transitional vertebra was observed.

\section{RESULTS}

A total of 108 dry adult human sacra were obtained to study the following morphological characteristics and variations.

Sacral Skewness: Sacral skewness was found in 8 sacra $(7.4 \%)$, with skewness being right sided in $5(4.6 \%)$ and left sided in 3 (2.8\%) sacra (Fig. 1, Table 1).

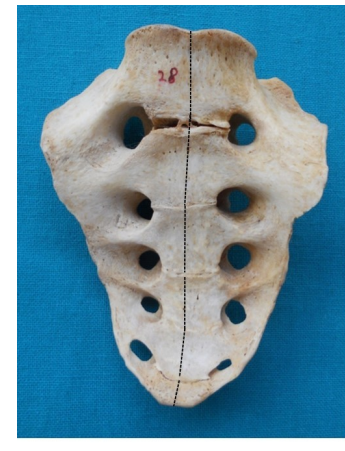

A

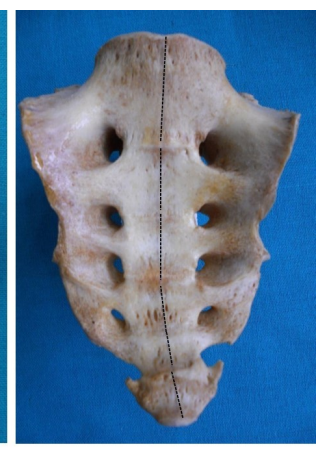

$B$
Fig. 1: Anterior surface of sacrum showing- A Right sided sacral skewness, B Left sided sacral skewness

\begin{tabular}{|c|c|c|c|}
\hline \multicolumn{2}{|c|}{ Sacral Skewness } & $\begin{array}{c}\text { Total } \\
(n=108)\end{array}$ & Percent \\
\hline \multicolumn{2}{|c|}{ Absent } & 100 & 92.6 \\
\hline \multirow{3}{*}{ Present } & Right & 5 & 4.6 \\
\hline & Left & 3 & 2.8 \\
\hline & Total & 8 & 7.4 \\
\hline
\end{tabular}

Table 1: Incidence and laterality of sacral skewness.
Auricular Surface: On the right side, the AS was flat in 13 and slightly concave in 95 sacra; while on the left side it was flat in 14 and slightly concave in 94 sacra (Fig. 2, Table 2).
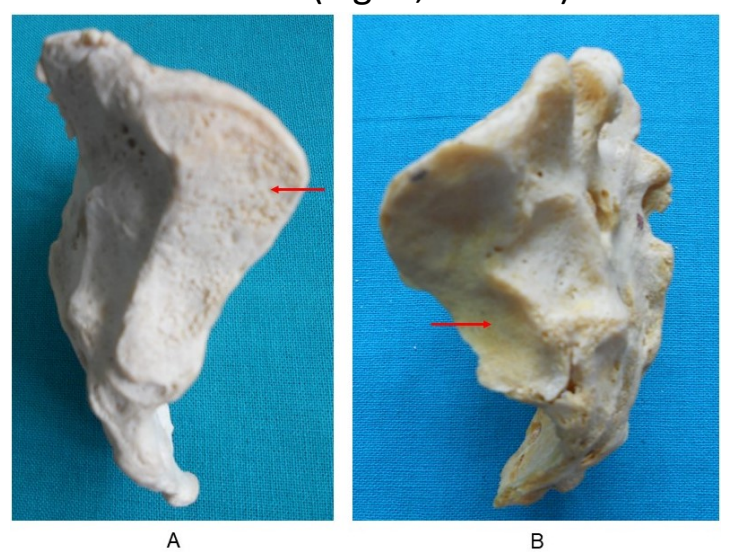

Fig. 2: Lateral aspect of the sacrum showing - AFlat auricular Surface B Slightly concave auricular Surface

Table 2: Morphological characteristics of auricular surface (AS).

\begin{tabular}{ccccc}
\hline AS & $\begin{array}{c}\text { Right AS } \\
(\mathbf{n = 1 0 8 )}\end{array}$ & Percent & $\begin{array}{c}\text { Left AS } \\
(\mathbf{n = 1 0 8 )}\end{array}$ & Percent \\
\hline \multicolumn{5}{c}{ Surface } \\
\hline Flat & 13 & 12 & 14 & 13 \\
\hline $\begin{array}{c}\text { Slightly } \\
\text { concave }\end{array}$ & 95 & 88 & 94 & 87 \\
\hline \multicolumn{5}{c}{ Location } \\
\hline S1-S2 & 4 & 3.7 & 4 & 3.7 \\
\hline S1-S3 & 103 & 95.4 & 103 & 95.4 \\
\hline S1-S4 & 1 & 0.9 & 1 & 0.9 \\
\hline
\end{tabular}

The most common location of AS was at the level of S1-S3 vertebrae, found in 103 (95.4\%) sacra The AS was located at the S1-S2 vertebral level in $4(3.7 \%)$ sacra and at the level of S1-S4 in one sacrum (0.9\%).

Accessory Auricular Surface: The presence of AAS was noted in 14 sacra (13\%). The AAS was found to be bilateral in 9 and was unilateral in 5 sacra (Table 3).

Table 3: Incidence and laterality of accessory auricular surface (AAS).

\begin{tabular}{ccc}
\hline AAS & $\begin{array}{c}\text { Total } \\
(\mathbf{n}=\mathbf{1 0 8})\end{array}$ & Percent \\
\hline Absent & 94 & 87 \\
\hline Present & 14 & 13 \\
\hline Bilateral & 9 & 8.4 \\
\hline Unilateral & 5 & 4.6 \\
\hline
\end{tabular}

AAS were observed to be of two shapes- crescent and oval. The crescent variety was found in 8 sacra on right side and in 5 sacra on left side. Oval articular surface was found in 6 sacra on right side and in 4 sacra on left side (Fig. 3, Table 4). 


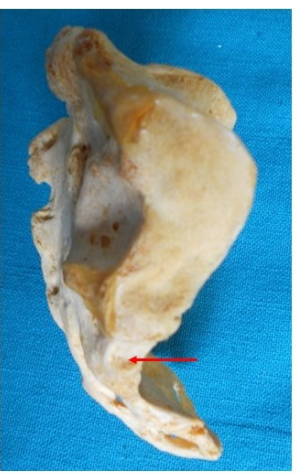

A

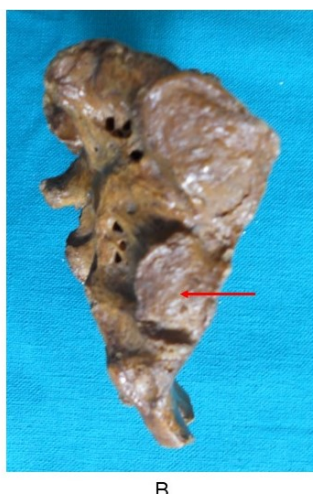

B
Fig. 3: Lateral aspect of the sacrum showingA Crescent shaped accessory auricular surface B Oval accessory auricular surface

Table 4: Morphological characteristics of accessory auricular surface.

\begin{tabular}{ccccc}
\hline AAS & $\begin{array}{c}\text { Right AAS } \\
(\mathbf{n}=\mathbf{1 4})\end{array}$ & Percent & $\begin{array}{c}\text { Left AAS } \\
(\mathbf{n}=\mathbf{9})\end{array}$ & Percent \\
\hline \multicolumn{6}{c}{ Shape } \\
\hline Crescent & 8 & 57.1 & 5 & 55.6 \\
\hline Oval & 6 & 42.9 & 4 & 44.4 \\
\hline \multicolumn{6}{c}{ Surface } \\
\hline Flat & 2 & 14.3 & 0 & 0 \\
\hline Slightly concave & 12 & 85.7 & 9 & 100 \\
\hline \multicolumn{6}{c}{ Location } \\
\hline S2 & 1 & 7.1 & 0 & 0 \\
\hline S3 & 12 & 85.7 & 9 & 100 \\
\hline S3-S4 & 1 & 7.1 & 0 & 0 \\
\hline
\end{tabular}

The AAS on the right side was flat in 2 and slightly concave in 12 sacra; while on the left side it was slightly concave in 9 sacra.

The location of AAS was seen at the level of S2 vertebra on the right side in 1 sacrum. AAS was at the level of S3 vertebra in 12 sacra on the right side and in 9 sacra on left side. It was found at the level of S3-S4 in only one sacrum. Sacra with bilateral accessory auricular surface were located at the level of S3 in all 9 sacra.

Spina Bifida: SB was observed in 12 sacra (11.1\%). It was most commonly located at S1 level (8.3\%). Only one sacrum $(0.9 \%)$ showed the non-closure at S1 and S2 and 2 sacra (1.8\%) showed non closure of S1 to S5 (Fig. 4, Table 5).

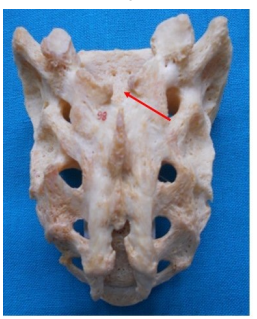

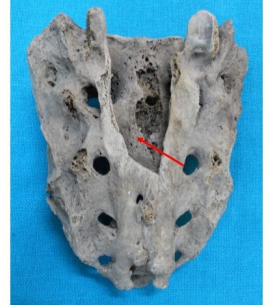

B

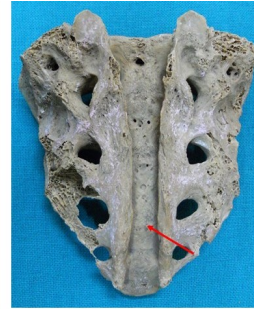

c
Fig. 4: Posterior surface of sacrum showing-

A Spina Bifida at S1 vertebral Level B Spina Bifida at S1, S2 vertebral Level

C Spina Bifida at S1, S2, S3, S4, S5 vertebral Level
Table 5: Incidence and vertebral level of spina bifida (SB).

\begin{tabular}{ccc}
\hline SB & $\begin{array}{c}\text { Total } \\
(\mathbf{n = 1 0 8 )}\end{array}$ & Percent \\
\hline Absent & 96 & 88.9 \\
\hline Present & 12 & 11.1 \\
\hline S1 & 9 & 8.3 \\
\hline S12 & 1 & 0.9 \\
\hline S12345 & 2 & 1.8 \\
\hline
\end{tabular}

Transitional Vertebra (Lumbar-Sacralization): Lumbo-sacral TV was seen in 11 sacra (10.2\%) (Fig. 5, Table 6).

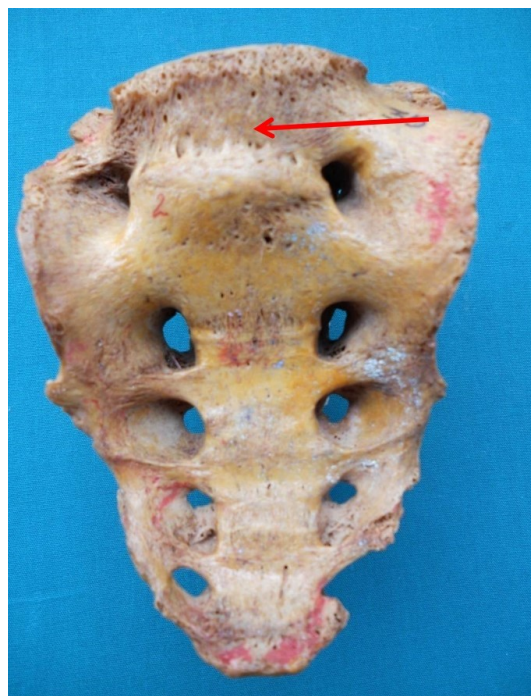

Fig. 5: Anterior surface of sacrum showing- Lumbarsacralization

Table 6: Incidence of lumbo-sacral transitional vertebrae (TV).

\begin{tabular}{ccc}
\hline TV & Total $(\mathbf{n = 1 0 8 )}$ & Percent \\
\hline Absent & 97 & 89.8 \\
\hline Present & 11 & 10.2 \\
\hline
\end{tabular}

\section{DISCUSSION}

The sacrum is an integral part of the spinal column and forms the posterosuperior wall of the pelvic cavity. Transmission of body weight from the vertebral column to the sacroiliac joints is made possible by the wedge-shaped interlocking mechanism of the articular surfaces of the sacroiliac joints. The sacrum is the target of various pathologies, fractures and instrumentation done for various spinal disorders.

The morphological variations of the sacrum assume clinical importance as the pelvic ring stability depends posteriorly on the sacroiliac joints. Skewness of sacrum can result in asymmetry of sacroiliac joint, which is likely to be misdiagnosed as sacroiliac joint 
subluxation [7].

Further the existence of transitional vertebrae increases the risk for development of nerveroot symptoms and may result in a vertebral level being wrongly identified unless preoperatively detected [14].

In the light of these facts, knowledge of morphological characteristics of the sacrum and its anatomical variations are clinically extremely important. The present study attempts to elucidate the morphological variations of dry adult human sacra in Indian population.

Skewness is a developmental asymmetry of the sacrum with the middle sagittal line of pelvic face of sacrum skewing to right or left. Presence of skewness results in asymmetry of sacroiliac joint. With increasing use of sacrum in various orthopaedic procedures for lumbosacral fixation, the recognition of sacral skewness poses significant importance.

In the present study, skewness was observed in $7.4 \%$ sacra in comparison to the finding of Wu LP (23.6\%). Sacral skewness was noted to be mostly right sided (4.6\%) which was similar to the finding of Wu LP in Chinese population. Higher incidence of right sided skewness may be postural due to more weight bearing on right lower limb during prolonged standing.

The most common extent of AS was from S1-S3 vertebrae, found in $95.4 \%$ sacra. The auricular surface was present at the S1-S2 vertebral level in $3.7 \%$ sacra. It was at the level of S1-S4 vertebrae in $0.9 \%$ sacrum. Different levels of AS may cause change in weight distribution pattern and elucidate many low back pain conditions [6]. The knowledge of extent of AS can be vital during sacroiliac joint instrumentation.

In present study, it was observed that AAS was present in $13 \%$ sacra. AAS was unilateral in $4.6 \%$ sacra; and bilateral in $8.4 \%$ sacra. The incidence and laterality were almost similar to study conducted by Wu LP et al.

The crescent-shaped AAS was most common and present in $57.1 \%$ sacra; while the oval surface, found in $42.9 \%$ sacra. The most of the AAS had slightly concave surfaces. Many researchers have encountered facets foraccessory sacroiliac articulations in roentgenographic examinations of patients, pelvic CT scans or in dried skeletons and did not investigate the qualitative morphological features [7, 8, 18-22] (Table 7).

In present study, the most common position of AAS was observed in $85.7 \%$ sacra at S3 level. Many researchers found the most common location of AAS at the level of the $2^{\text {nd }}$ dorsal sacral foramina $[8,18,19]$. Valojerdy MR et al. found the AAS at the level of 1st dorsal sacral foramina [20] (Table 7). The AAS take part in weight transmission proportionate to their size and can be a cause of low back pain due to change in line of weight transmission. Furthermore, the acquaintance of morphological characteristics of AAS can be crucial during sacroiliac joint instrumentation.

Many authors have reported varying data on the incidence of SB in different populations with most common occurrence at S1 level [7, 16]. In the present study, SB was found to be present in $11.1 \%$ sacra which was comparable to the finding of Ali $S$ et al in Pakistani population [23]. The frequency of occurrence of spina bifida varies widely ranging from $4.5 \%$ in British Population to $61.5 \%$ in Chinese population (Table 8) [24-30]. The most common vertebral level of SB was found to be at S1 (75\% of SB cases) in our study which is similar to other investigators $[9,16]$. Present study on dry adult sacra seems to have greater accuracy as direct visual observation of the sacrum is more objective than inspection of radiographs and $\mathrm{CT}$ scans. Variations in the frequency of spina bifida may be due to different methods of acquiring data and classifying the condition and also it may be related to genetic endowment and environmental conditions of different population which can alter the occurrence of anatomical variations [31].

The incidence of transitional vertebrae has been reported to be variable in different populations, with fewer incidence of lumbarization being documented. Although reduction of the sacral constituents is less common, lumbarization of $1^{\text {st }}$ sacral vertebra does happen which may be totally or partially separate [1]. 
Table 7: Comparison of AAS between previous and present studies.

\begin{tabular}{|c|c|c|c|c|c|c|}
\hline Researcher & Population & No. of sacra & Frequency & Laterality & Location & Data source \\
\hline Trotter M [18] [1940] & American & 958 & $36 \%$ & $\begin{array}{l}\text { U/L: } 50 \% \\
\text { B/L:50\% }\end{array}$ & S2 PSF & Dry adult sacra \\
\hline \multirow{2}{*}{ Hadley LA [19] [1952] } & \multirow{2}{*}{ American } & 185 & $18 \%$ & U/L: $58 \%$ & \multirow{2}{*}{ S2 PSF } & Dry adult sacra \\
\hline & & 200 & $33.50 \%$ & B/L:42\% & & Radiographs \\
\hline \multirow{2}{*}{ Ehara S et al. [1988] } & \multirow{2}{*}{ American } & 100 & $13 \%$ & U/L: 5(55.6\%) & \multirow{2}{*}{ S2 PSF } & CT scan \\
\hline & & 56 & $16 \%$ & B/L:3(33.3\%) & & Dried skeletons \\
\hline \multirow{2}{*}{ Valojerdy MR et al. [20] [1990] } & \multirow{2}{*}{ British } & \multirow{2}{*}{153} & \multirow{2}{*}{$18 \%$} & U/L:65\% & \multirow{2}{*}{ S1 PSF } & \multirow{2}{*}{ Dry adult sacra } \\
\hline & & & & B/L: $35 \%$ & & \\
\hline Prassopoulos PK et al. [21] [1999] & Greek & 534 & $19.10 \%$ & -- & -- & CT scan-Pelvis \\
\hline \multirow{2}{*}{ Demir M et al. [22] [2007] } & \multirow{2}{*}{ Turkish } & \multirow{2}{*}{400} & \multirow{2}{*}{$17.50 \%$} & U/L:46(65.7\%) & \multirow{2}{*}{-} & \multirow{2}{*}{ CT scan- Pelvis } \\
\hline & & & & B/L:24(34.3\%) & & \\
\hline \multirow{2}{*}{ Wu LP et al. [2009] } & \multirow{2}{*}{ Chinese } & \multirow{2}{*}{203} & \multirow{2}{*}{$12.30 \%$} & U/L:9(36\%) & \multirow{2}{*}{$\begin{array}{l}\text { Postero- } \\
\text { inferior }\end{array}$} & \multirow{2}{*}{ Dry adult sacra } \\
\hline & & & & B/L:16(64\%) & & \\
\hline \multirow{2}{*}{ Present study } & \multirow{2}{*}{ Indian } & \multirow{2}{*}{108} & \multirow{2}{*}{$12.90 \%$} & U/L:5(35.7\%) & \multirow{2}{*}{ S3 } & \multirow{2}{*}{ Dry adult sacra } \\
\hline & & & & B/L:9(64.3\%) & & \\
\hline
\end{tabular}

Table 8: Comparison between previous and present studies on SB.

\begin{tabular}{lcccc}
\hline \multicolumn{1}{c}{ Researcher } & Population & $\begin{array}{c}\text { No. of dry } \\
\text { sacra/Radiograph/CT }\end{array}$ & Frequency & Data Source \\
\hline Lorber J et al. [24] [1967] & British & 200 & $4.50 \%$ & Radiographs \\
\hline Vannier JP et al. [25] [1981] & French & 299 & $8.40 \%$ & Radiographs \\
\hline Boone D et al. [26] [1985] & British & 653 & $17.30 \%$ & Radiographs \\
\hline Fidas A et al. [27] [1987] & British & 2707 & $23 \%$ & Radiographs \\
\hline Saluja PG [1988] & British & 140 & $15.70 \%$ & Radiographs \\
\hline Avrahami E et al. [28] [1994] & Israeli & 1200 & $17 \%$ & Radiographs \& CT \\
\hline Thorpe AC et al. [29] [1994] & British & Control:48 & $22.90 \%$ & Radiographs \\
\hline Taskaynatan MA et al. [2005] & Turkish & Cases:52 & $82.60 \%$ & Radiographs \\
\hline Secer M et al. [2009] & Turkish & 401 & $8.50 \%$ & Radiographs \\
\hline Wu LP et al. [2009] & Chinese & 203 & $28.10 \%$ & Dry sacra \\
\hline Ali S et al. [2014] & Pakistani & 200 & $10.50 \%$ & Dry sacra \\
\hline Li W et al. [30] [2021] & Chinese & 148 & $61.50 \%$ & Radiographs \\
\hline Present study & Indian & 108 & $11.10 \%$ & Dry adult sacra \\
\hline
\end{tabular}

Table 9: Comparison between previous and present studies on TV.

\begin{tabular}{lcccc}
\hline \multicolumn{1}{c}{ Researcher } & Population & $\begin{array}{c}\text { No. of dry } \\
\text { sacra/Radiograph/CT }\end{array}$ & Frequency & Data Source \\
\hline Moore BH [31] [1925] & American & 87 & $3.40 \%$ & Skeletons \\
& & 1104 & $3.35 \%$ & Radiographs \\
\hline O'Driscoll CM et al. [32] [1996] & British & 100 & $15 \%$ & Radiographs \\
\hline Vergauwen S et al. [1997] & Belgian & 350 & $37 \%$ & Radiographs \\
\hline Olofin MU et al. [2001] & Nigerian & 300 & $13 \%$ case & Radiographs \\
\hline Otani K et al. [33] [2001] & Japanese & 501 & $11 \%$ control & Radiographs \\
\hline Taskaynatan MA et al. [2005] & Turkish & 508 & $13.40 \%$ & MRI \\
\hline Hughes RJ et al. [34] [2006] & British & 881 & $13.90 \%$ & MRI \\
\hline Lee CH et al. [35] [2007] & Korean & 500 & $4.50 \%$ & Radiographs \\
\hline Secer M et al. [2009] & Turkish & 534 & $16.70 \%$ & Dry adult sacra \\
\hline Wu LP et al. [2009] & Chinese & 401 & $4.10 \%$ & Radiographs \\
\hline French HD et al. [36] [2014] & Australian & 293 & $11.90 \%$ & Radiographs \\
\hline Bhattarai M [37] [2018] & Nepalese & 5941 & $10.20 \%$ & Dry adult sacra \\
\hline Present study & Indian & 947 & 108 & $15 \%$ \\
\hline
\end{tabular}

The present study showed transitional verte- observed higher incidence of TV in comparibra in $10.2 \%$ sacra. Moore BH in American son to Indian population (Table 9) [31-37]. population, Taskaynatan MA et al. and Secer Olofin $\mathrm{MU}$ et al. observed the highest $M$ et al. in Turkish Population and French HD incidence of TV (37\%) in Nigerian population et al. in Australian population reported [12].The knowledge of occurrence of TV is of lowerincidence of TV while other researchers utmost important for clinicians as it may be 
associated with increased risk of disc degeneration, disc herniation and stenosis of spinal canal and neural foramina [17].

\section{CONCLUSION}

Sacrum is highly variable bone exhibiting variations such as skewness, AAS, SB and TV. Frequency of occurrence of such variations also differs in various populations which may be related to genetic endowment and different environmental conditions. Variations of the sacrum may be involved in many clinical conditions such as stenosis of spinal canal and neural foramina, nerve-root compression, disc degeneration, posterior disc herniation, backache, enuresis, neurological abnormalities of the lower limb and functional disorders of lower urinary tract. Ultimately, the thorough knowledge of sacral variations is crucial for surgeons performing lumbosacral and sacroiliac instrumentation and the present study might be useful for them.

\section{ABBREVIATIONS}

AS: Auricular surface

AAS: Accessory auricular surface

SB: Spina Bifida

TV: Transitional vertebra

\section{Authors' contribution}

Sandeep Saluja- Acquisition of data and its analysis Sneh Agarwal- Conception \& design of manuscript Anita Tuli- Analysis and interpretation of data Shashi Raheja- Final approval of the version to be published

Sarika Rachel Tigga- Drafting of manuscript and its revision

\section{Conflicts of Interests: None}

\section{REFERENCES}

[1]. Standring S, Newell RLM, editors. Gray's Anatomy: The anatomical basis of clinical practice. $40^{\text {th }}$ Spain: Churchill Livingstone Elsevier;2008.

[2]. Sinnatamby CS, editor. Last's anatomy: Regional and applied. $12^{\text {th }}$ ed. China: Churchill Livingstone Elsevier;2006.

[3]. Snell RS. Clinical anatomy by regions. $8^{\text {th }}$ ed. New Delhi: Wolters Kluwer (India) Pvt. Ltd;2008.

[4]. Pal GP. Weight transmission through the sacrum in man. J Anat 1989;162: 9-17.

[5]. Flander LB, Corruccini RS. Shape differences in the sacral alae. Am J Phys Anthropol 1980;52(3):399403.

[6]. Mahato NK. Variable positions of the sacral auricular surface: classification and importance. Neurosurg focus 2010;28(3):E12.
[7]. Wu LP, Li YK, Li YM, Zhang YQ, Zhong SH. Variable morphology of the sacrum in a Chinese population. Clin Anat 2009;22(5):619-626.

[8]. Ehara S, El-khoury GY, Bergman RA. The accessory sacroiliac joint: A common anatomical variant. AJR 1988;150(4):857-859.

[9]. Saluja PG. The incidence of spina bifida occulta in a historic and a modern London population. J. Anat. 1988;158:91-93.

[10]. Senoglu N, Senoglu M, Gumusalan Y. Total spina bifida occulta of the sacrum. International Journal of anatomic variations 2008;1:26-27.

[11]. Srijit D, Shipra P. Spina bifida with higher position of sacral hiatus: a case report with clinical implication. Bratisl Lek Listy 2007;108(10-11) :467-469.

[12]. Olofin MU, Noronha C, Okanlawon A. Incidence of lumbosacral transitional vertebrae in low back pain patients. West Afr J Radiol. 2001;8:1-6.

[13]. Vergauwen S, Parizel PM, Van Breusegem L, Van Goethem JW, Nackaerts Y, Van den Hauwe L, De Schepper AM. Distribution and incidence of degenerative spine changes in patients with a lumbosacral transitional vertebra. European Spine Journal. 1997;6(3):168-172.

[14]. Grainger RG, Allison DJ, Adam A, Dixon AK eds. Diagnostic Radiology: A text book of medical imaging. China: Churchill Livingstone Elsevier;2001.

[15]. Taskaynatan MA, Izci Y, Ozgul A, Hazneci B, Dursun $H$, Kalyon TA. Clinical significance of congenital lumbosacral malformations in young male population with prolonged low back pain. Spine. 2005;30(8):E210-3.

[16]. Secer M, Muradov JM, Dalgiç A. Evaluation of congenital lumbosacral malformations and neurological findings in patients with low back pain. Turk Neurosurg. 2009;19(2):145-148.

[17]. Bron JL, Royan BJV, Wuisman PIJM. The clinical significance of lumbosacral transitional anomalies. Acta orthop. Belg. 2007;( 73):687-695.

[18]. Trotter M. A common anatomical variation in the sacro-iliac region. The journal of bone \& joint surgery. 1940;22(2):293-299.

[19]. Hadley LA. Accessory sacro-iliac articulations. The journal of bone \& joint surgery. 1952;34(1):149155.

[20]. Valojerdy MR, Hogg DA. Anatomical note: The occurrence of accessory sacroiliac joints in man. Clin Anat 1990;3(4):257-258.

[21].Prassopoulos PK, Faflia CP, Voloudaki, AE, Gourtsoyiannis NC. Sacroiliac Joints: Anatomical Variants on CT. Journal of Computer Assisted Tomography. 1999;23(2): 323-327.

[22]. Demir M, Mavi A, Gumusburun E, Bayram M, Gursoy S. Anatomic variation with joint space measurements on CT. Kobe J. Med. Sci. 2007;53(5):209217.

[23]. Ali S, Azeemi AA, Shoukat S. The prevalence of spina bifida occulta in Pakistani population: A study of dry human sacra. Anaesth Pain Intensive Care. 2019;18(2):157-161. 
[24]. Lorber J, Levick K. Spina bifida cystica. Incidence of spina bifida occulta in parents and in controls. Arch Dis Child 1967;42:171-173.

[25]. Vannier JP, Lefort J, Cavelier B, Ledosseur P, Assailly C, Feingold J. Spina bifida cystica families x-ray examination and HLA typing. Pediatr Res. 1981;15(4 Pt 1):326-9.

[26]. Boone D, Parsons D, Lachmann SM, Sherwood T. Spina bifida occulta: lesion or anomaly? Clin Radiol. 1985;36(2):159-161.

[27]. Fidas A, MacDonald HL, Elton RA, Wild SR, Chisholm GD, Scott R. Prevalence and pattern of spina bifida occulta in 2707 normal adult. Clin Radiol. 1987;38(5): 537-542.

[28]. Avrahami E, Frishman E, Fridman Z, Azor M. Spina bifida occulta of S1 is not an innocent finding. Spine 1994;19(1):12-15.

[29]. Thorpe AC, Evans RE, Williams NS. Constipation and spina bifida occulta: is there an association? J R Coll Surg Edinb. 1994;39(4):221-224.

[30]. Li W, Xiong Z, Dong C, Song J, Zhang L, Zhou J et al. Distribution and imaging characteristics of spina bifida occulta in young people with low back pain: a retrospective cross-sectional study. J Orthop Surg Res. 2021;16(1):1-8.

[31]. Albrecht TL, Scutter SD, Henneberg M. Radiographic method to assess the prevalence of sacral spina bifida occulta. Clin Anat. 2007;20(2):170-174.
[32]. O'Driscoll CM, Irwin A, Saifuddin A. Variations in morphology of the lumbosacral junction on sagittal MRI: correlation with plain radiography. Skelet Radiol. 1996 Apr;25(3):225-230.

[33]. Otani K, Konno S, Kikuchi S. Lumbosacral transitional vertebrae and nerve-root symptoms. J Bone Joint Surg Br 2001;83(8):1137-40.

[34]. Hughes RJ, Saifuddin A. Numbering of lumbosacral transitional vertebrae on MRI: role of the iliolumbar ligaments. Am J Roentgenol. 2006 Jul;187(1):W59-65.

[35]. Lee CH, Park CM, Kim KA, Hong SJ, Seol HY, Kim BH et al. Identification and prediction of transitional vertebrae on imaging studies: anatomical significance of paraspinal structures. Clin Anat. 2007;20(8):905-14.

[36]. French HD, Somasundaram AJ, Schaefer NR, Laherty RW. Lumbosacral transitional vertebrae and its prevalence in the Australian population. Global spine journal. 2014;4(4):229-32.

[37]. Bhattarai M. A hospital based plain radiographic observational study of lumbosacral transitional vertebrae in the Nepalese population. Asian Journal of Medical Sciences. 2018;9(4):46-50.

How to cite this article:

Sandeep Saluja, Sneh Agarwal, Anita Tuli, Shashi Raheja, Sarika Rachel Tigga. Morphological Variations of Sacrum in Adult Indian Population. Int J Anat Res 2022;10(1):8230-8237. DOI: 10.16965/ijar.2021.193 